\title{
Pharmaceutical Quality/CMC Test Usage Terminology
}

National Cancer Institute

\section{Source}

National Cancer Institute. Pharmaceutical Quality/CMC Test Usage Terminology. NCI

Thesaurus. Code C133868.

A category of terminology used to qualify the information pertaining to test usage in the framework of the Pharmaceutical Quality/Chemistry, Manufacturing and Controls documents. 